\title{
Energy Efficient Three Phase Squirrel Cage Induction Motor fed AC Drives
}

\author{
D. Edison Selvaraj \\ Panimalar Engineering College \\ Chennai, India
}

\section{S. Geethadevi}

Aurora Scientific and

Technological Institute

Uppal, Hyderabad, India

\author{
C. Ruban Karthik \\ Mepco Schlenk Engg. College \\ Sivakasi, India
}

R. Arun

Mepco Schlenk Engg. College

Sivakasi, India

\begin{abstract}
Three phase squirrel cage induction motors consume $60 \%$ of industrial electricity. $1 \%$ increase in efficiency of all the motors in India will save 500 MW powers which needs the initial generation cost of 2000 crores. The efficiency of an induction motor can be substantially improved by controlling the voltage to frequency ratio $(\mathrm{V} / \mathrm{Hz})$. Another method of improving the efficiency of induction motor was coating enameled copper wire filled with Al2O3 nano filler. One such method used in this project was carried out under serious literature survey. Based on the previous project works, actions were taken to use the enamel filled with nano filler as the coating for the induction motor to improve its efficiency. Definitely, there will be a tremendous improvement in the efficiency of the induction motor and hence the motor can be called as "High Efficiency Squirrel Cage Induction Motor".
\end{abstract}

Keywords: Induction motor, Enamel, Nano fillers, Load test, Efficiency

\section{INTRODUCTION}

Induction motors were widely used in fans, centrifugal pumps, blowers, lifts, cranes, hoists and so on. The efficiency of the induction motor depends upon the insulation used [1-3]. For motors, the enamel was used for three purposes: impregnation, coating and adhesion. The efficiency of the induction motor can be increased by adding the nano fillers with the enamel which was used as coating for the windings of the motor [3-6]. In this paper, the efficiency of the normal three phase squirrel cage induction motor and the $\mathrm{Al}_{2} \mathrm{O}_{3}$ nano filled enamel coated three phase squirrel cage induction motor was analyzed and the results were compared with each other.

\section{PREPARATION AND CHARACTERIZATION OF $\mathrm{AL}_{2} \mathrm{O}_{3} \mathrm{NANO}$ FILLER}

The micro powders of $\mathrm{Al}_{2} \mathrm{O}_{3}$ were crushed into nano powders by Ball Mill method. The SEM images of $\mathrm{Al}_{2} \mathrm{O}_{3}$ before and after Ball Mill show the particle size of the powders. The particle size was augment by SEM images [7-9]. These SEM results show that the prepared particles of $\mathrm{Al}_{2} \mathrm{O}_{3}$ were in the nm range.

\subsection{SEM analysis before Synthesization}

The particle size of $\mathrm{Al}_{2} \mathrm{O}_{3}$ before ball mill method was shown in Figure 1.

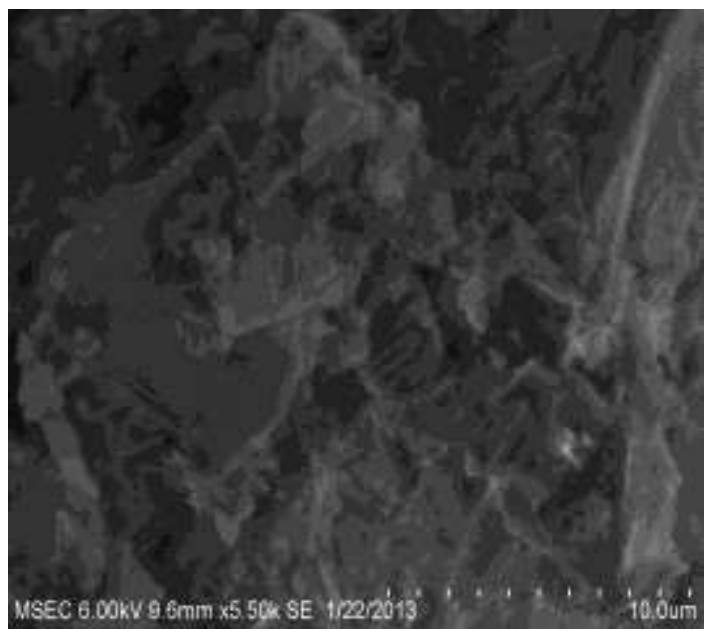

Figure $1 \mathrm{SEM}$ analysis of $\mathrm{Al}_{2} \mathrm{O}_{3}$ at $10 \mu \mathrm{m}$

\subsection{SEM analysis After Synthesisation}

From the analyzed SEM image the particles were in the form of nano metric range varies for one area to other. The sizes of the particles as shown in figure 2 were in the range from 40 to $100 \mathrm{~nm}$ size. 


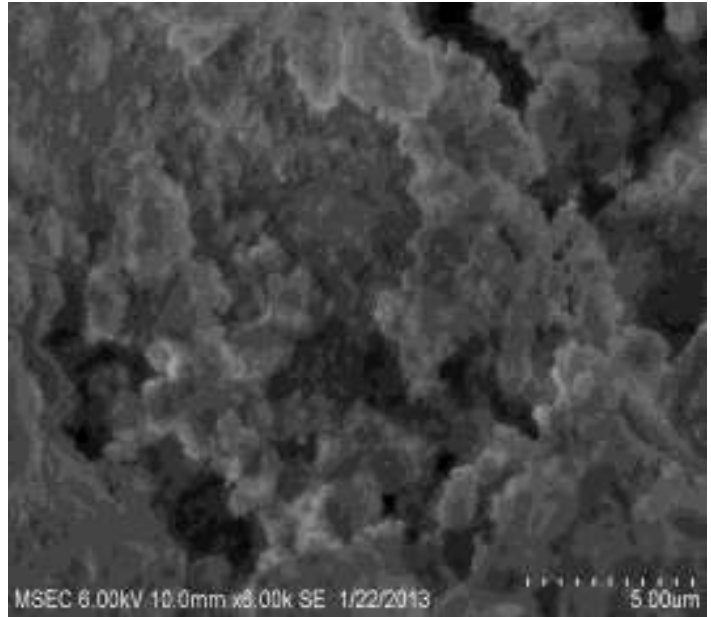

Figure 2 SEM analysis of $\mathrm{Al}_{2} \mathrm{O}_{3}$ at $5 \mu \mathrm{m}$

\section{COATING OF THE $\mathrm{AL}_{2} \mathrm{O}_{3}$ NANO FILLED ENAMEL TO THE WINDINGS OF THE MOTOR}

The nano powder of $\mathrm{Al}_{2} \mathrm{O}_{3}$ were taken and mixed with the enamel by using ultrasonic vibrator [9-12]. Further, this enamel was coated on the windings of the three phase squirrel cage induction motor. The Figure 5 shows the $\mathrm{Al}_{2} \mathrm{O}_{3}$ Nano filled enamel coated Induction motor.

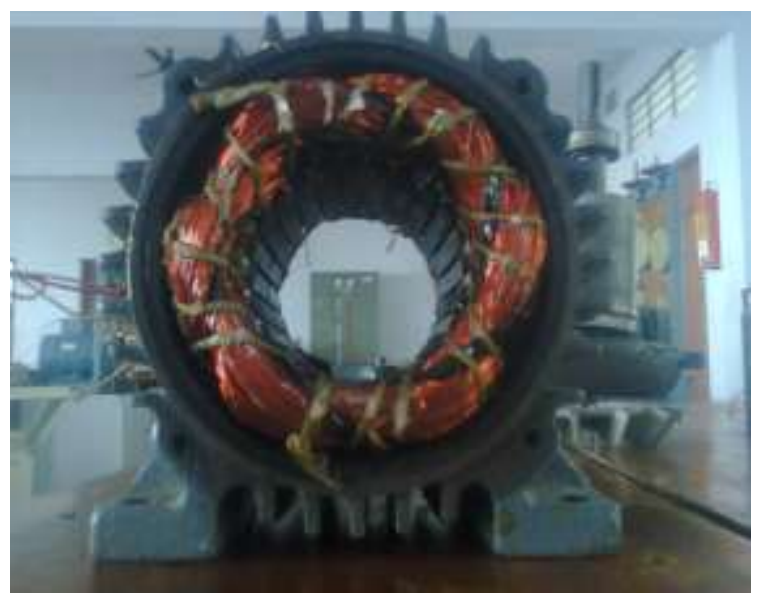

Figure $5 \mathrm{Al}_{2} \mathrm{O}_{3}$ Nanocomposite filled enamel coated Induction motor

The specifications of the three phase squirrel cage induction motor were shown below in the Table 1 .

Table 1 Specifications of the three phase squirrel cage induction motor

\begin{tabular}{|c|c|}
\hline Quantity & Rating \\
\hline Power & $1.5 \mathrm{HP}$ \\
\hline Speed & $1450 \mathrm{rpm}$ \\
\hline Current & $3.45 \mathrm{~A}$ \\
\hline Voltage & 415 \\
\hline
\end{tabular}

\section{EXPERIMENTAL ANALYSIS}

\subsection{Performance Analysis of Squirrel Cage} Induction Motor - Circle diagram Method

This analysis was done by doing open and short circuit test. By calculating the open and short circuit current and voltage the losses were found using circle diagram method. From the circle diagram it was found that the losses were reduced in nano coated motor. It was shown in the table 2 and 3.

Table 2 Open circuit and short circuit test readings for ordinary induction motor

\begin{tabular}{|l|c|c|c|}
\hline Open & Voc & Ioc & Woc \\
\cline { 2 - 4 } Circuit Test & 415 & 1.3 & 80 \\
\hline Short & Vsc & Isc & Wsc \\
\cline { 2 - 4 } Circuit Test & 95 & 3.45 & 210 \\
\hline
\end{tabular}

Table 3 Open circuit and short circuit test readings for Nanocoated induction motor

\begin{tabular}{|l|c|c|c|}
\hline Open & Voc & Ioc & Woc \\
\cline { 2 - 4 } Circuit Test & 415 & 1.3 & 65 \\
\hline Short & Vsc & Isc & Wsc \\
\cline { 2 - 4 } Circuit Test & 95 & 3.45 & 180 \\
\hline
\end{tabular}

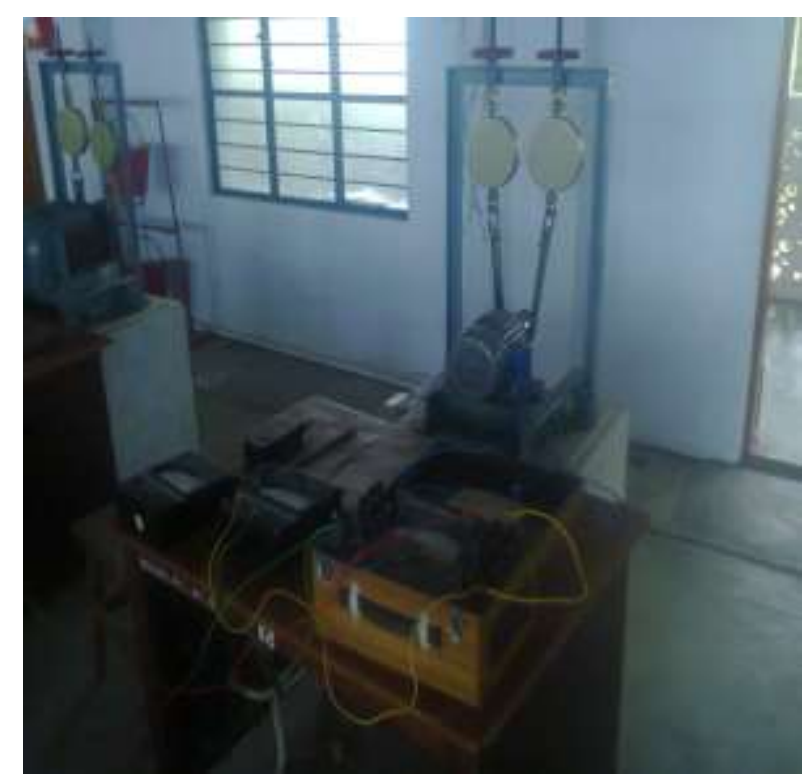

Figure 6 Snap shot of open and short circuit test

Efficiency was analyzed by conducting load test in ordinary as well stator enameled with nano composite motor [11-13]. The results obtained were successful for nano coated motor. The efficiency of nano coated motor increased to 4 percent. This is mainly due to reduction of dielectric losses in nano coated motor. The readings were calculated for various slip values and shown in Table 4. Figure 7 shows the Efficiency comparison of various motors. 
Table 4 Efficiency comparison for ordinary and nano coated motor

\begin{tabular}{|c|c|c|}
\hline Slip & $\begin{array}{c}\text { Efficiency of } \\
\text { normal induction } \\
\text { motor in \% }\end{array}$ & $\begin{array}{c}\text { Efficiency of nano } \\
\text { coated induction } \\
\text { motor in \% }\end{array}$ \\
\hline 0.02 & 74.95 & 79.07 \\
\hline 0.04 & 71.5 & 76.32 \\
\hline 0.06 & 67.50 & 72.73 \\
\hline 0.08 & 63 & 67.3 \\
\hline 0.1 & 59.85 & 63.8 \\
\hline
\end{tabular}

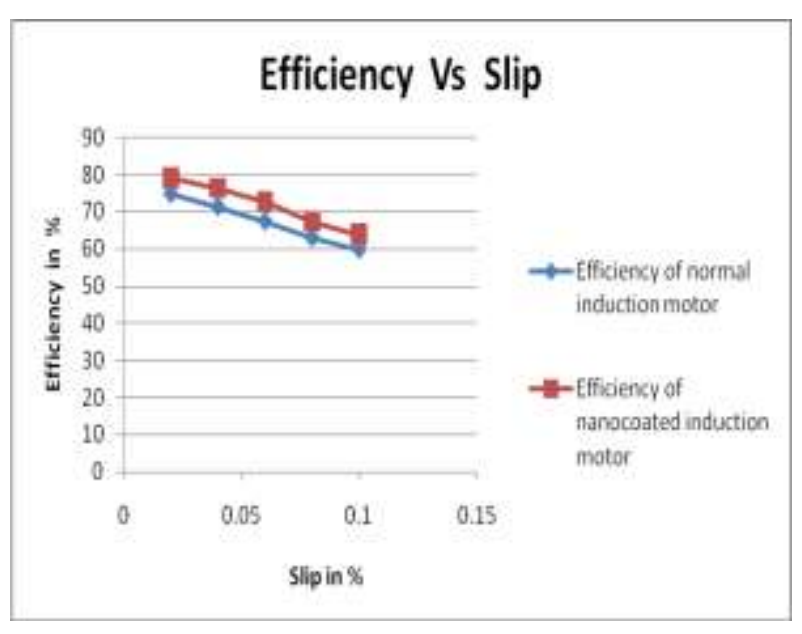

Figure 7 Efficiency comparison of various motors

\subsection{Performance Analysis of Squirrel Cage Induction Motor - Direct loading Method}

The load test was conducted on the ordinary induction motor and the nano coated indution motor. The performance of the motor were obtained for induction motor by this method. The output power, current, efficiency, powerfactor and speed of the motor were measured during this testing. The maximum efficiency obtained from an ordinary induction motor was $75 \%$. The maximum efficiency obtained from nano coated induction motor was $79 \%$. The efficiency of the motor was increased due to the reduction in harmonic and dielectric losses.

\section{CONCLUSION}

The efficiency of the induction motor was increased by $4 \%$ by adding $\mathrm{Al}_{2} \mathrm{O}_{3}$ nano filler to the enamel used as the coating for the windings of the three phase squirrel cage induction motor. Hence, the overall performance of the induction motor was also increased by adding $\mathrm{Al}_{2} \mathrm{O}_{3}$ nano filler to the enamel used in the induction motor. The speed fluctuations were also less and smooth when compared to that of the ordinary induction motor.

\section{ACKNOWLEDGEMENT}

Thank God and His almighty power to finish His research work by using me, my project guide and my parents for His ultimate work.

\section{REFERENCES}

[1] Selvaraj, D. Edison, et al. "Analysis of Efficiency, Thermal Withstanding Capacity and Electromagnetic Interference of Three Phase Squirrel Cage Induction Motor Coated with $\mathrm{SiO}_{2}$ \& $\mathrm{TiO}_{2}$ nano composite Filled Enamel." International Journalof Science and Engineering Applications 1.1 (2012): 17-21.

[2] Edison Selvaraj, D., C. Pugazhendhi Sugumaran, and A. Sivaprakash."Characterization Of Electrical and Thermal Properties of Enamel Filled with Carbon Nanotubes." Proceedings of the Third International Conference on Trends in Information, Telecommunication and Computing. Springer New York, 2013.

[3] Selvaraj, D. Edison. "Partial discharge characteristics of enamel filled with micro and nano composite of $\mathrm{siO}_{2}$ and $\mathrm{TiO}_{2}$." International Journal of Science and Engineering Applications 1.2 (2012): 95-101.

[4] Selvaraj, D. Edison. "Characterization of dielectric properties of the enamel filled with carbon nano tubes for the frequency range of 50 $\mathrm{Hz}-5 \mathrm{MHz}$ International Journal of Science and Engineering Applications 1.2 (2012): 102106.

[5] Selvaraj, D. Edison, and C. Pugazhendhi Sugumaran. "Comparative Analysis of Dielectric Properties of Enamel Filled with Various Nano fillers such as $\mathrm{ZrO}_{2}, \mathrm{Al}_{2} \mathrm{O}_{3}, \mathrm{CNT}$ and $\mathrm{ZnO}$." International Journal of Science and Engineering Applications 1.1 (2012): 51-55.

[6] Babu, B. Gurukarthik, D. Edison Selvaraj, R. Srinivas, B. Guru Prakash, and R. Vishnu. "Analysis of Relative Permittivity and Tan Delta Characteristics of Silicone Rubber Based Nano-composites." International Journal of Scientific Engineering and Technology, pp.2201206, 2012.

[7] D.EdisonSelvaraj,J.Ganesan. "Experimental Analysis of Efficiency and Thermal Withstanding Capacity of Three Phase Squirrel Cage Induction Motor Coated with $\mathrm{SiO}_{2} \& \quad \mathrm{TiO}_{2} \quad \mathrm{Nano}$ Composite Filled Enamel", International Journal of Engineering Sciences, Vol (2), No (4), 2013. pp. 115-118. 
Lieutenant Ganesan. J, Jeyadevi.S.Dr, and Edison Selvaraj. D, "Performance Analysis of Single Phase Induction Motor Coated with $\mathrm{Al}_{2} \mathrm{O}_{3}$ Nano Filler Mixed Enamel" ACEEE International Journal on Recent Trends in Engineering \& Technology Vol. 10, No. 1, Jan 2014.

[9] Edison Selvaraj. D, Pugazhendhi Sugumaran. C, Lieutenant Ganesan. J, Ramathilagam. J, "Analysis of Dielectric and Thermal Properties of Polyamide Enamel Filled with Carbon Nano tubes" International Journal of Nano science, Vol.12, Issue 3, June 2013.

[10] Lieutenant Ganesan. J, Edison Selvaraj. D, and Ramathilagam. J,"Experimental analysis of Thermal conductivity of enamel filled with micro and nano composite of $\mathrm{SiO}_{2}$ and $\mathrm{TiO}_{2}$ " International journal of Advanced Research in Electrical, Electronics and Instrumentation Engineering, Vol.2, Issue 7,pp. 2907-2912, 2013.

[11] Lieutenant Ganesan. J, Jeyadevi. S. Dr, and Edison Selvaraj. D, "Reduction of Electromagnetic Interference in Single Phase Induction Motor by coating the winding with $\mathrm{Al}_{2} \mathrm{O}_{3}$ nano filler mixed Enamel" International journal of Advanced Research in Electrical, Electronics and Instrumentation Engineering, Vol.2, Issue7,pp. 2913-2916, 2013.

[12] Lieutenant Ganesan. J, Edison Selvaraj. D, and Selva Kumar. B, "High Efficiency Induction Motor", International journal of Advanced Research in Electrical, Electronics and Instrumentation Engineering, Vol.2, Issue 2, pp. 750-754, 2013.

[13] Lieutenant Ganesan. J, and Edison Selvaraj. D, "Analysis of Thermal and Electrical Properties of Enamel Filled with Various Nano fillers such as $\mathrm{ZrO} 2, \mathrm{Al} 2 \mathrm{O} 3$ and CNT", International Journal of Engineering Research, Vol.2, Issue 2, pp. 182-186, 2013. 